\title{
O risco sanitário na comercialização de alimentos em um mercado público da Amazônia: um estudo de caso em Belém
} (PA)

The sanitary risk in food commercialization in an amazon public market: a case study in Belém

\author{
M. Y. O. Rosa ${ }^{1}$, F. F. Borges ${ }^{1}$, L. N. Correa Junior², F. H. S. Lobato ${ }^{3 *}$ \\ ${ }^{1}$ Universidade do Estado do Pará(UEPA), Centro de Ciências Naturais e Tecnologia, 66095-100, Belém, Pará, Brasil. \\ ${ }^{2}$ Universidade Federal do Pará (UFPA), Pós-graduação Lato Sensu em Geografia e Meio Ambiente (Campus \\ Ananindeua), 67130-660, Ananindeua, Pará, Brasil. \\ ${ }^{3}$ Universidade Federal do Pará (UFPA), Pós-graduação em Desenvolvimento Sustentável do Trópico Úmido \\ (PPGDSTU/NAEA), 66075-110, Belém, Pará, Brasil.
}

*flaviohslobato@gmail.com

(Recebido em 19 de agosto de 2019; aceito em 01 de outubro de 2019)

\begin{abstract}
Esta pesquisa objetivou avaliar as condições higiênico-sanitárias do pescado comercializado no Mercado Municipal de Icoaraci, Belém (PA), a fim de verificar se os locais de armazenamento e as práticas de manipulação de alimentos, durante a comercialização, estão em consonância com as determinações de instrumentos normativos do Ministério da Agricultura, Pecuária e Abastecimento (MAPA). A coleta de dados se deu a partir da aplicação de um questionário junto a cinco feirantes, contendo 13 itens e 112 quesitos, baseados na Portaria 2.619/2011 do Estado de São Paulo e na Resolução-RDC no 275/2002. Os resultados evidenciaram a precária estrutura do mercado e dos pontos de venda, bem como a falta de conhecimento técnico dos feirantes acerca das Boas Práticas de Fabricação de Alimentos (BPF).

Palavras-chave: Condições higiênico-sanitárias, Pescado, Mercado Municipal de Icoaraci.
\end{abstract}

This research aimed to evaluate the hygienic-sanitary conditions of fish marketed in the Municipal Market of Icoaraci, Belém (PA), to verify if storage locations and food handling practices, are in line with the determinations of the Ministério da Agricultura, Pecuária e Abastecimento (MAPA). Data collection was based on the application of a questionnaire to five marketers, containing 13 items and 112 items, based on the Ordinance 2.619/2011 of the State of São Paulo and Resolution RDC N ${ }^{\circ} .275 / 2002$. The results showed the precarious structure of the market and points of sale, as well as the lack of technical knowledge of the marketers about the Good Manufacturing Practices (GMP).

Keywords: Hygienic and sanitary conditions, Fish, Municipal Market of Icoaraci.

\section{INTRODUÇÃO}

Historicamente, as feiras e os mercados populares foram espaços concebidos para fins de abastecimento, sendo locais onde é possível adquirir produtos e serviços a preços acessíveis [1]. Contudo, a comercialização de alimentos nesses lugares pode resultar em riscos à saúde dos consumidores, visto que os alimentos são expostos a situações que facilitam a sua contaminação, entre as quais destacam-se: a contaminação por parte do(a) manipulador(a) quando não adota práticas apropriadas de manipulação, a exposição dos alimentos a estruturas precárias para a venda e as irregulares formas de armazenamento dos alimentos [2]. Assim, não raro, esses alimentos estão contaminados por micro-organismos patogênicos, em face das péssimas condições de armazenamento e da falta de conhecimento técnico por parte dos comerciantes [3].

Diante disso, no Brasil, diversos instrumentos normativos foram criados com vistas a disciplinar e garantir a comercialização de alimentos em condições salubres. Nessa direção, destaca-se a Portaria n 326/1997 [4], que aprovou o regulamento técnico para as condições higiênico-sanitárias e de boas práticas de manipulação de alimentos para estabelecimentos produtores e/ou 
industrializadores de alimentos, e a Instrução Normativa $n^{\circ}$ 16/2017 [5], a qual propõe melhorias técnicas às boas práticas e aos procedimentos operacionais para estabelecimentos e serviços de alimentação, a fim de assegurar as condições higiênico-sanitárias dos alimentos.

No tocante aos pescados, cumpre destacar que são alimentos ricos em vitaminas (A e D) e em minerais, como: cálcio, ferro e fósforo, apresentando altos índices de ácidos graxos essenciais, como o ômega-3, o qual é associado à redução do risco de doenças cardiovasculares e às importantes fases do desenvolvimento do ser humano [6]. No entanto, o pescado é um alimento altamente vulnerável à deterioração por conta de sua composição química e do seu pH que, por ser neutro, facilita a expansão microbiana [7]. Neste contexto, os benefícios nutricionais deste grupo alimentar só podem ser aproveitados quando os fatores segurança e qualidade forem garantidos, tornando-se fundamental o emprego de ferramentas que possam agir na contenção dos mecanismos de deterioração, como o emprego da cadeia do frio em todas as etapas do seu processamento [8]. À vista disso, a Portaria $\mathrm{n}^{\circ}$ 326/1997 [4] determina que os estabelecimentos destinados a comercializarem pescados e seus derivados devem dispor de instalações adequadas, com especial atenção à manipulação.

Destarte, as boas práticas de fabricação, de manipulação e comercialização de alimentos de qualquer produto são primaciais para a inocuidade em todos os processos da cadeia de produção, uma vez que ajudam a assegurar o controle de qualidade, a segurança e a soberania alimentar. Assim, seguindo o que dispõe os instrumentos normativos, as instituições e os órgãos reguladores, os locais de comercialização e os manipuladores devem adotar procedimentos de boas práticas de manipulação, com vistas a garantir a qualidade higiênico-sanitária dos produtos comercializados $[4,5,9,1011]$.

Em investigações recentes no Estado do Pará [12, 13] e em outros locais do país [14, 15], evidenciou-se que as pesquisas realizam suas análises centradas na qualidade dos pescados e dos locais de comercialização. Assim, num prisma legalista, os estudos são realizados a partir de fichas de verificação (check list) para avaliar as conformidades higiênico-sanitárias, baseando-se em leis, decretos, portarias e/ou resoluções brasileiras $[9,10]$. No entanto, a partir dos espaços onde realizaram-se estudos envolvendo condições higiênico-sanitárias em Belém [16, 17], verificou-se que não existe nenhum estudo anterior sobre os mercados e feiras de Distrito de Icoaraci, o que indica a necessidade de realizar estudos para avaliar a qualidade dos alimentos comercializados nesses espaços.

Diante dessa lacuna, este trabalho tem sua relevância ao buscar contribuir com a geração de novos conhecimentos sobre os alimentos comercializados nesta localidade, tendo como objetivo avaliar especificamente as condições higiênico-sanitárias dos pontos de venda de pescados do Mercado Municipal de Icoaraci, em Belém (PA), com o propósito de analisar se estão em consonância com as disposições legais, bem como de identificar o nível de conhecimento dos vendedores referente às boas práticas de manipulação de alimentos.

\section{MATERIAL E MÉTODOS}

A metodologia foi instituída por uma abordagem quantitativa de caráter avaliativo. Para elaboração, foi empregada como técnica de pesquisa a pesquisa de campo. Esta ocorreu nos dias 19 e 21 de abril de 2019 (final de semana de Páscoa), a partir de observação sistemática e da aplicação de um questionário junto a cinco (5) feirantes no Mercado Municipal de Icoaraci, Belém (PA). A amostra de cinco feirantes corresponde a $62,5 \%$ do total (oito feirantes) de pontos de comercialização de pescados do referido mercado. Convém pontuar que todos os sujeitos foram convidados a participar da pesquisa de forma espontânea e voluntária, por meio da assinatura do Termo de Consentimento Livre e Esclarecido (TCLE), a qual foi antecedida de uma conversa para explicar sobre a utilização dos dados, do TCLE e a relevância da pesquisa.

Tal instrumento de coleta de dados abrangeu 13 itens e 112 quesitos essenciais de higiene e de boas práticas de fabricação para alimentos produzidos e comercializados para o consumo humano, a saber: 1) Recebimento/compra; 2) Armazenamento em câmara fria; 3) Geladeira/freezer/balcão frigorífico; 4) Manipulação; 5) Área de exposição de venda; 6) Água; 7) Resíduos; 8) Controle integrado de pragas; 9) Instalações/edificações; 10) Sanitários e vestiários; 11) Higiene das instalações; 12) Documentação; e 13) Manipuladores. Importa salientar que o questionário baseou- 
se no Roteiro de inspeção de açougues e peixarias, anexo da Portaria 2.619/2011 [9] da Coordenação de Vigilância em Saúde, da Secretaria Municipal de Saúde de São Paulo.

As opções de resposta para o complemento da lista de verificação foram: 1) Conformidade (C) - caso o quesito fosse atendido; 2). Não conformidade (NC) - caso o quesito não fosse atendido; 3 ) Não Aplicável (NA) - caso o quesito não fosse pertinente; 4) Não Observado (NO) - caso o quesito não fosse observado no local da pesquisa. Destarte, a análise dos dados se deu a partir de um percentual estatístico, obtido através da fórmula do índice de conformidade:

$$
\% \text { Conformidade }=\frac{\text { total de requisitos }- \text { quesitos não verificados }}{\text { quesitos conformes }} \times \frac{100 \%}{X \%}
$$

Posteriormente aos cálculos dos percentuais, a classificação da conformidade dos locais de venda foi realizada partindo de instruções das Boas Práticas de Fabricação (BPF), da Resolução RDC n ${ }^{\circ}$ 275/2002 [10], englobando os requisitos primordiais pela legislação quanto à preparação e à manipulação de alimentos, como mostra a Tabela 1.

Tabela 1: Classificação do nível de conformidade dos pontos de venda.

\begin{tabular}{c|c|c|c}
\hline Classificação & Conformidade (\%) & \multicolumn{2}{|c}{ Situação } \\
\hline Grupo 1 & De 75 a 100 & Excelente (E) & \\
\hline Grupo 2 & De 51 a 74 & Bom (B) & \\
\hline Grupo 3 & $\leq 50$ & Ruim (R) & \\
\hline
\end{tabular}

\section{RESULTADOS E DISCUSSÃO}

A partir dos dados coletados, observou-se que nenhum dos pontos de comercialização apresentou percentuais de conformidade maior que $50 \%$, sendo todos classificados como "Ruim", de acordo com a Tabela 2, a qual trata da classificação do nível de conformidade dos pontos de venda. Tal resultado representa uma situação preocupante no que diz respeito à segurança alimentar e à saúde, pois o Mercado Municipal de Icoaraci configura-se como sendo um dos principais pontos de venda da região.

Tabela 2 - Conformidades dos pontos de venda de pescado no Mercado Municipal de Icoaraci, Belém $(P A)$.

\begin{tabular}{|c|c|c|c|c|c|c|}
\hline \multicolumn{7}{|c|}{ CONFORMIDADES DOS PONTOS DE VENDA DO MERCADO (C\%) } \\
\hline & P. 1 & P. 2 & P. 3 & P. 4 & P. 5 & MCS\% \\
\hline 1. Recebimento/ Compra & $0 \%$ & $0 \%$ & $0 \%$ & $0 \%$ & $0 \%$ & $\mathbf{0 \%}$ \\
\hline $\begin{array}{l}\text { 2. Armazenamento em câmara } \\
\text { fria }\end{array}$ & $0 \%$ & $0 \%$ & $0 \%$ & $0 \%$ & $0 \%$ & $\mathbf{0 \%}$ \\
\hline $\begin{array}{l}\text { 3. Geladeira/Freezer/Balcão } \\
\text { Frigorífico }\end{array}$ & $0 \%$ & $0 \%$ & $0 \%$ & $0 \%$ & $0 \%$ & $\mathbf{0 \%}$ \\
\hline 4. Manipulação & $8,3 \%$ & $8,3 \%$ & $0 \%$ & $8,33 \%$ & $0 \%$ & $6,65 \%$ \\
\hline 5. Área de exposição de venda & NA & NA & NA & NA & NA & NA \\
\hline 6. Água & $33,33 \%$ & $33,33 \%$ & $33,33 \%$ & $33,33 \%$ & $33,33 \%$ & $\mathbf{3 3}, \mathbf{3 3} \%$ \\
\hline 7. Resíduos & $0 \%$ & $0 \%$ & $0 \%$ & $0 \%$ & $0 \%$ & 0\% \\
\hline $\begin{array}{l}\text { 8. Controle Integrado de } \\
\text { Pragas }\end{array}$ & $0 \%$ & $0 \%$ & $0 \%$ & $0 \%$ & $0 \%$ & 0\% \\
\hline 9. Instalações/ Edificações & $11,1 \%$ & $11,1 \%$ & $11,1 \%$ & $11,1 \%$ & $11,1 \%$ & $11,11 \%$ \\
\hline 10. Sanitários e vestiários & $0 \%$ & $0 \%$ & $0 \%$ & $0 \%$ & $0 \%$ & $0 \%$ \\
\hline 11. Higiene das instalações & $0 \%$ & $0 \%$ & $0 \%$ & $0 \%$ & $0 \%$ & $\mathbf{0 \%}$ \\
\hline 12. Documentação & $0 \%$ & $0 \%$ & $0 \%$ & $0 \%$ & $0 \%$ & $0 \%$ \\
\hline
\end{tabular}




\begin{tabular}{l|c|c|c|c|c|c}
\hline 13. Manipuladores & $0 \%$ & $6,25 \%$ & $6,25 \%$ & $43,75 \%$ & $12,5 \%$ & $\mathbf{1 4 \%}$ \\
\hline Conformidade Geral (\%) & $\mathbf{4 \%}$ & $\mathbf{5 \%}$ & $\mathbf{4 \%}$ & $\mathbf{9 \%}$ & $\mathbf{5 \%}$ & $\mathbf{5 \%}$ \\
\hline Situação & RUIM & RUIM & RUIM & RUIM & RUIM & RUIM \\
\hline
\end{tabular}

C\%: conformidade; P: ponto de venda 1-5; MCS\%: média de conformidade por seção; NA: não se aplica.

Ao pormenorizar a análise acerca dos 13 itens avaliados, de acordo com os dados, os feirantes dos cinco pontos (P1, P2, P3, P4 e P5) não correspondiam com nenhum dos requisitos do item "1. Recebimento/compra", uma vez que eles não informaram qual a procedência e de que forma os peixes chegavam ao mercado, dificultando assim conclusões acerca do recebimento destes produtos. Pereira et al. [18], nesse sentido, salientam que no transporte dos pescados deve haver bastante cuidado, os caminhões precisam estar limpos e ser de uso exclusivo de produtos pesqueiros, totalmente isotérmico e o pescado completamente envolto em gelo.

Acerca dos itens " 2 . Armazenamento em câmara fria" e "3. Geladeira/freezer/balcão frigorífico", a avaliação evidenciou $0 \%$ de conformidade. Entretanto, com relação ao item "3. Geladeira/freezer/balcão frigorífico", os pontos P2, P3 e P5 possuíam freezer, mas apenas o feirante do ponto P5 utilizava para armazenamento do produto, ainda que em más condições de higiene e armazenamento e não estando de acordo com nenhum requisito de uso. Com efeito, não apresentando conformidade com o que determina instrumentos normativos, como a Resolução$\mathrm{RDC} \mathrm{n}^{\circ}$ 275/2002 [10]. Não obstante a realidade investigada, no Mercado do Ver-o-Peso, também em Belém (PA) em estudo similar [16], constatou-se que os peixes ficavam expostos sem qualquer refrigeração, ou os que utilizavam colocavam pouco gelo, o que não ajuda na conservação. Por outro lado, em um estudo realizado em um mercado de peixes de Teresina (PI) em 2018, os pescados analisados encontravam-se em temperatura conforme com os padrões da legislação, estando entre 0 e $-3^{\circ} \mathrm{C}[14]$.

Ademais, o uso do frio é muito importante após a captura, visto que rapidamente os peixes começam o processo de decomposição: em virtude da baixa temperatura, são ativadas as atividades enzimáticas e bacterianas, iniciando o processo de deterioração. Portanto, recomenda-se que para o peixe resfriado ter uma boa conservação, a temperatura deve estar entre $-0^{\circ} \mathrm{C}$ e $-2^{\circ} \mathrm{C}$; e para os congelados, a temperatura precisa estar entre $-15^{\circ} \mathrm{C}$ e $-25^{\circ} \mathrm{C}[18,19]$. É notório que os feirantes preferem manter os seus pescados sob a refrigeração em gelo por ser mais barato, no entanto, devese ficar em alerta em relação a isso, pois normalmente os peixes são submetidos a quantidades insuficientes de gelo, o que contribui para a sua não conservação. Do mesmo modo, deve-se atentar para a qualidade deste gelo, que também pode contribuir para a proliferação microbiana e contaminação dos pescados [20,21].

Segundo a Portaria $n^{\circ}$ 2619/2011 da Prefeitura de São Paulo [9], é proibida a entrada e permanência de caixas de madeira nos locais em que estão sendo manipulados os alimentos, visto que contribuem para o acúmulo de sujidades. No entanto, quanto ao item "4. Manipulação", somente no P1 não foi constatada a presença de caixas de madeira e/ou papelão na área de manipulação, resultando em uma conformidade de $8,3 \%$. Seguindo as informações que compõem essa Portaria [9], é proibida a utilização de lã de aço ou objetos abrasivos na limpeza dos equipamentos, em virtude da corrosão dos mesmos. Porém, apenas o feirante do P2 segue as determinações deste quesito, resultando em conformidade de $8,3 \%$. No quesito uniformes, apenas o feirante do P4 assinalou que seu uniforme e os panos utilizados na limpeza do ponto eram lavados fora da área onde o alimento era manipulado.

Os locais onde os alimentos são expostos à venda devem estar adequadamente protegidos contra poeiras, insetos e quaisquer pragas urbanas, assim como devem permanecer distantes de produtos químicos e tóxicos para que evite a contaminação dos produtos que estão sendo comercializados, conforme o Art. 33 da Instrução Normativa no 16/2017 [5]. Contudo, no item "5. Área de exposição de venda", pode-se observar que as condições encontradas nos pontos de venda do mercado estão totalmente em discordância, em virtude de que os alimentos ficam expostos sem nenhum cuidado, ao ar livre, para que sejam vistos mais facilmente pelos clientes.

No tópico referente à " 6 . Água", os cinco feirantes apresentaram conformidade com o seguinte quesito do item. Segundo a Instrução Normativa $n^{\circ}$ 16/2017 [5], a água para o consumo direto e para o preparo dos alimentos deve ser oriunda do abastecimento público, desde que a mesma seja 
de fácil acesso e esteja em boas condições de consumo, ademais, deve passar frequentemente por análises laboratoriais para que comprove a boa qualidade da água. Conforme o observado na pesquisa de campo, além dos pontos de venda não possuírem locais exclusivos de coleta de água, os quais contam com torneiras espalhadas pelas instalações do mercado, a água não passa por análises laboratoriais periodicamente. Desse modo, houve uma conformidade de apenas 33,3\%.

Quando se trata do item "7. Resíduos", todos os pontos (P1, P2, P3, P4 e P5) não apresentaram conformidade em nenhum dos requisitos dos respectivos itens, apresentando consequentemente $0 \%$ de conformidade. Evidenciou-se, pois, que não havia um descarte correto dos restos dos pescados e de outros produtos que eram comercializados no mercado, sendo descartados em lixeiras abertas sem nenhum tipo de proteção. Acerca disso, o Roteiro de Inspeção de Açougues e Peixarias, afirma que os resíduos sólidos devem ser separados dos orgânicos em recipientes com tampa, pedal, fabricados de materiais de fácil limpeza e revestidos com sacos plásticos a fim de que possam ser removidos sempre que necessário [9].

Ao avaliar o item "8. Controle integrado de pragas", todos os pontos (P1, P2, P3, P4 e P5) também não apresentaram conformidade em nenhum dos requisitos dos respectivos itens. $\mathrm{O}$ mercado não contava com um controle de pragas e havia valas e caixas de gordura sem qualquer tampa de proteção, bem como portas e janelas sem quaisquer telas para inibição da entrada de insetos e animais. Desse modo, constatou-se que as instalações do mercado se encontravam bastante danificadas em virtude de sua não manutenção, condição imprescindível para a Vigilância Sanitária [4].

Em relação ao item "9. Instalações /edificações", todos os pontos apresentam em comum a conformidade no que diz respeito ao estabelecimento possuir acesso livre, independente e sem comunicação direta com dependências residenciais. No entanto, nenhum dos pontos mostrou conformidade nos demais quesitos referentes a instalações. Logo, apresentaram $11,1 \%$ de conformidade nesse item. Acerca disso, ao contrário do que determina a Portaria 2.619/2011 da Secretaria Municipal de Saúde de São Paulo [9], as instalações não eram "[...] mantidas limpas, organizadas, em boas condições de conservação, livres de focos de insalubridades, pragas, vetores urbanos, outros animais, materiais em desuso, inservíveis e estranhos à atividade“. Em trabalho similar [16], outros pesquisadores assinalam que as instalações do Mercado Ver-o-Peso, também com localização na cidade de Belém, apresentavam-se fora dos padrões, pois ainda que existisse uma estrutura ampla e adequada, percebia-se muita sujidade no teto, nas paredes e nos ralos espalhados pelo mercado, sendo comum se observar restos dos pescados no mercado.

Percebeu-se que não houve cumprimento dos requisitos por parte de nenhum dos cinco feirantes para os itens 10, 11 e 12. "10. Sanitários e vestiários", dado que esses espaços encontravam-se em péssimas condições de uso, sem qualquer higienização e manutenção. "11. Higiene das instalações": não havia limpeza diária nas instalações do mercado, uma vez que somente se jogava água no chão. Outrossim, em outras avaliações, como na cidade de Palmas (TO) [22], constatou-se similaridades com esta pesquisa, uma vez que não apresentavam tanto sanitários quanto vestiários para os frequentadores e as que tinham os banheiros, $80 \%$ apresentaram-se inadequadas, uma vez que estavam em situação precária e inapropriada para uso. "12. Documentação", em virtude de que não possuíam os requisitos básicos para manipular alimentos, quais sejam: o certificado de curso de manipulação e, seguidamente, a carteira de autorização para este fim [9], consequentemente todos obtiveram na avaliação $0 \%$ de conformidade nos 3 itens.

A Resolução $n^{\circ}$ 216/2004 [11], que dispõe regulamentos técnicos de boas práticas em serviços de alimentação, apresenta orientações para pessoas que trabalham na manipulação de alimentos possam seguir e se adequar às normas estabelecidas por Lei. Entre as orientações pode-se destacar o controle de saúde dos manipuladores, os quais devem: evitar apresentar lesões ou sintomas de enfermidade para que não contaminem o alimento que está sendo manipulado; manter os uniformes limpos; ser bastante cuidadosos em relação à higiene das mãos; entre outras.

Em consonância com a resolução, acerca do item "13. Manipuladores", o feirante do P1 não apresentou conformidade em nenhum quesito deste item. Todavia, os feirantes dos pontos 2 e 3 (P2 e P3) não apresentavam adornos, maquiagens, esmaltes ou piercings, e apresentavam-se devidamente asseados, cumprindo os requisitos 6 e 7 deste item, lhes dando 6,25\% de conformidade. $\mathrm{O}$ feirante do ponto 4 (P4), apresentou conformidade em seis requisitos deste item, os quais eram: possuir carteira de manipulador de alimentos; participar de curso de boas práticas 
(sendo estes requisitos básicos para manipulação de alimentos); possuir exames de saúde em dia; não fazer uso de adornos; estar asseado e com a barba feita. Ele foi o único que cumpriu com os requisitos 2 e 3 deste item, tendo como resultado, 43,7\% de conformidade.

\section{CONCLUSÃO}

Este trabalho, ao buscar investigar a realidade do Mercado Municipal de Icoaraci, Belém (PA), no que concerne às condições higiênico-sanitárias, revelou que os consumidores deste local estão expostos ao risco de contaminação a partir da ingestão de alimentos adquiridos em seu interior, tendo em vista que os pescados são manipulados e armazenados sob péssimas condições. Ao se basear em instrumentos normativos consolidados, evidenciou-se que as condições infraestruturais do mercado - somadas ao pouco conhecimento técnico e à realização de atividades irregulares por parte dos feirantes - conformam um ambiente completamente inapropriado para a comercialização de pescados, figurando um espaço propício para a contaminação de alimentos e a proliferação de Doenças Veiculadas por Alimentos (DVAs).

Diante desse preocupante cenário, entende-se que para minimizar ou superar os problemas identificados neste estudo, é emergente a aplicação de cursos de boas práticas de manipulação e o emprego de Procedimentos Operacionais Padrão (POPs). A partir de tais medidas, os feirantes poderão realizar corretamente as ações de limpeza, de manipulação, de armazenamento e de transporte, com vistas a oferecer um produto de qualidade e sem riscos à saúde do consumidor.

\section{REFERÊNCIAS BIBLIOGRÁFICAS}

1. Lobato FHS, Ravena-Cañete, V. Farinha de feira: memórias e identidades de vendedores em feiras do bairro do Guamá, Belém (PA). Iluminuras. 2015 Jan/Jun;16(37):242-271.

2. Souza CO, Chaves-Filho GP, Melo KKF, Fernandes MB, Rocha SF, Machado AL. Perfil da qualidade higiênico-sanitária de carnes comercializadas em feiras livres do Município de Paus dos Ferros/RN Brasil. Congresso Norte e Nordeste de Pesquisa e Inovação 7; 2012 Out 19-21; Palmas, TO. Palmas: IFTO, 2012.

3. Soto FRM, Risseto MR, Lúcio D, Shimozako HJ, Camargo CC, Iwata MK, Camargo CA, Oliveira E, Camargo SR. Metodologia de avaliação das condições sanitárias de vendedores ambulantes de alimentos no Município de Ibiúna-SP. Rev Bras Epidemiol. 2008;11(2):297-303. doi: 10.1590/S1415$790 X 2008000200011$.

4. Brasil. Portaria SVS/MS no 326, de 30 de julho de 1997. Aprovar o Regulamento Técnico; "Condições Higiênicos-Sanitárias e de Boas Práticas de Fabricação para Estabelecimentos Produtores/Industrializadores de Alimentos". Brasília (DF): Ministério da Saúde; 1997.

5. Distrito Federal. Instrução Normativa $N^{\circ} 16$, de 23 de maio de 2017. Aprovar a atualização do anexo da Instrução Normativa $\mathrm{n}^{\circ}$ 4, de 15 de dezembro de 2014, que aprovou o regulamento técnico sobre boas práticas para estabelecimentos comerciais de alimentos e para serviços de alimentação. Brasília (DF): Sistema Integrado de Normas Jurídicas do Distrito Federal; 2017.

6. Silva ML, Matté GR, Matté MH. Aspectos sanitários da comercialização de pescado em feiras livres da cidade de São Paulo, SP/Brasil. Aspectos sanitários da comercialização de pescado em feiras livres da cidade de São Paulo, SP/Brasil. Rev Inst Adolfo Lutz. 2008;67(3):208-214.

7. Franco BGMB, Landgraf M. Microbiologia dos alimentos. São Paulo: Atheneu; 2008.

8. Soares, KMP, Gonçalves, AA. Qualidade e segurança do pescado. Rev. Inst. Adolfo Lutz. 2012; 71(1): $1-10$.

9. São Paulo. Roteiro de inspeção - açougue e peixaria. São Paulo: Prefeitura de São Paulo; 2011.

10. Brasil. Resolução de Diretoria Colegiada - RDC no 275, de 21 de outubro de 2002. Dispõe sobre o Regulamento Técnico de Procedimentos Operacionais Padronizados aplicados aos Estabelecimentos Produtores/Industrializadores de Alimentos e a Lista de Verificação das Boas Práticas de Fabricação em Estabelecimentos Produtores/Industrializadores de Alimentos. Brasília (DF): Ministério da Saúde; 2002.

11. Brasil. Resolução $n^{\circ}$ 216, de 15 de setembro de 2004. Dispõe sobre Regulamento de Boas Práticas para Serviços de Alimentação. Brasília (DF): Ministério da Saúde; 2004.

12. Silva FNL, Oliveira LC, Mangas TP, Santos AS, Sampaio LSO, Macedo ARG, Cordeiro CAM. Perfil higiênico-sanitários durante a venda do camarão-da-Amazônia (Macrobrachium amazonicum) na cidade de Breves (Marajó, estado do Pará, Brasil). Acta Fish Aquatic Res. 2017;5(3):21-7.

13. Souza TM, Atayde HM. Educação higiênico-sanitária dos feirantes do Mercadão 2000 e Feira do Pescado em Santarém-PA. Rev Bras Ext Univers. 2017 set/dez;8(3):127-34. 
14. Santos GM, Cavalcanti BS, Sampaio MMR, Bomfim AV, Leal MJB. Avaliação das condições higiênicosanitárias de manipuladores e verificação da temperatura de comercialização do pescado em um mercado de peixe de Teresina-PI. Rev Eletr FAINOR. 2018 jan/abr;11(1):123-34.

15. Sousa FA, Rodrigues RA, Arruda FA, Santos WLM, Santos TM. Caracterização higiênico-sanitária e tecnológica dos pescadores e da tilápia do nilo (Oreochromis niloticus) comercializada no mercado municipal de Salinas-MG. Rev Bras Ci Veter 2017 out/dez;24(4):197-200.

16. Alves EMP, Silva A, Sousa CL, Figueiredo HM, Neves EA. Aspectos higiênico-sanitários das instalações do Mercado Ver-o-peso e avaliações de temperatura dos peixes comercializados. Rev Eletr FAINOR. 2017 jun/jul;10(2):25-43.

17. Miranda BDS, Vinagre EF. Avaliação das condições higiênico-sanitárias de carne bovina moída comercializada em açougues de Belém-PA [Trabalho de Conclusão de Curso]. Belém (PA): Universidade do Estado do Pará; 2018.

18. Pereira DS, Julião L, Sucasas LFA, Silva LKS, Galvão JA, Oetterer M. Boas práticas para manipulação de pescado: o pescado e o uso do frio. Piracibaca: USP; Nov 2009. 10/15 p.

19. Brasil. Cartilha da semana do peixe. Brasília (DF): Agência Nacional de Vigilância Sanitária; 2016. 143p.

20. Viana ICLA, Valiatti TB, Sobral FOS, Romão NF, Fonseca CX, Oliveira UA. Análise microbiológica do tambaqui (Colossoma macropomum) comercializado na feira municipal de Ariquemes, Estado de Rondônia, Brasil. Rev Pan-Amazônica Saúde 2016;7(2):67-73.

21. Pauli ER. Índice de qualidade de peixes comercializados em feiras livres na Cidade de Rio Verde - Goiás [Trabalho de Conclusão de Curso]. Rio Verde (GO): Instituto Federal de Educação, Ciência e Tecnologia Goiano; 2019.

22. Paiva MJM, Anjos ESD, Costa RF, Zuniga ADG. Avaliação das condições higiênico-sanitárias da comercialização de pescado em feiras livres de Palmas-TO. Rev Desafios 2018;5(4):117-23. 